Article

\title{
Closing the Circle of the Lanthanide-Murexide Series: Single-Molecule Magnet Behavior and Near-Infrared Emission of the $\mathrm{Nd}^{\mathrm{III}}$ Derivative
}

\author{
Gang Huang, Guillaume Calvez ${ }^{\mathbb{D}}$, Yan Suffren ${ }^{\mathbb{D}}$, Carole Daiguebonne, Stéphane Freslon, \\ Olivier Guillou and Kevin Bernot*iD \\ Univ Rennes, INSA Rennes, CNRS, UMR 6226 (Institut des Sciences Chimiques de Rennes), \\ F-35000 Rennes, France; h710377768@163.com (G.H.); guillaume.calvez@insa-rennes.fr (G.C.); \\ yan.suffren@insa-rennes.fr (Y.S.); carole.daiguebonne@insa-rennes.fr (C.D.); \\ stephane.freslon@insa-rennes.fr (S.F.); Olivier.guillou@insa-rennes.fr (O.G.) \\ * Correspondence: kevin.bernot@insa-rennes.fr; Tel.: +33-02-2323-8434
}

Received: 18 July 2018; Accepted: 21 September 2018; Published: 1 October 2018

\begin{abstract}
Up to now, even if murexide-based complexometric studies are performed with all $3 d$ or $4 f$ ions, the crystal structures of the light-lanthanide derivatives of the lanthanide-murexide series are unknown. In this work, we report the crystal structure of the $\mathrm{Nd}^{\mathrm{III}}$ derivative named NdMurex. Contrary to all known complexes of the $3 d$ or $4 f$ series, a dimeric compound was obtained. As for its already reported $\mathrm{Dy}$ III and $\mathrm{Yb}^{\mathrm{III}}$ parents, the $\mathrm{Nd}^{\mathrm{III}}$ complex responsible for the color-change behaves as a single-molecule magnet (SMM). This behavior was observed on both the crystalline (NdMurex: $\mathrm{U}_{\text {eff }}=6.20(0.80) \mathrm{K}, 4.31 \mathrm{~cm}^{-1} ; \tau_{0}=2.20(0.92) \times 10^{-5} \mathrm{~s}, \mathrm{H}_{\mathrm{dc}}=1200 \mathrm{Oe}$ ) and anhydrous form (NdMurexAnhy: $\mathrm{U}_{\text {eff }}=6.25(0.90) \mathrm{K}, 4.34 \mathrm{~cm}^{-1} ; \tau_{0}=4.85(0.40) \times 10^{-5} \mathrm{~s}, \mathrm{H}_{\mathrm{dc}}=1200 \mathrm{Oe}$ ). The SMM behavior is reported also for the anhydrous Ce $\mathrm{e}^{\mathrm{III}}$ derivative (CeMurexAnhy: $\mathrm{U}_{\text {eff }}=5.40(0.75) \mathrm{K}$, $\left.3.75 \mathrm{~cm}^{-1} ; \tau_{0}=3.02(1.10) \times 10^{-5} \mathrm{~s}, \mathrm{H}_{\mathrm{dc}}=400 \mathrm{Oe}\right)$. The Near-Infrared Emission NIR emission was observed for NdMurexAnhy and highlights its bifunctionality.
\end{abstract}

Keywords: lanthanides; neodymium single-molecule magnets; near-infrared emission; bifunctionality

\section{Introduction}

The interest for multifunctional magnetic material has been boosted by the (re)introduction of lanthanide ions [1] in the field of molecular magnetism [2-4]. Indeed, in addition to their appealing magnetic properties they have also intrinsic assets such as catalytic activity or photo-luminescent properties [5-10]. This last point opens the way to magnetic and luminescent materials that can be of particular interest [11-13].

Murexide ligand (Scheme 1) is also known as purpuric acid or ammonium salt of 2,6-dioxo-5[(2,4,6-trioxo-5-hexahydropyrimidinylidene)amino]-3H-pyrimidin-4-olate, abbreviated $\left(\mathrm{NH}_{4} \mathrm{~L}\right)[14,15]$. This ligand has been widely used in complexometric studies with $3 d$ or $4 f$ ions [16-19]. The complexation triggered a very strong color-change from purple to red-orange either in water or in organic solvent [14,16-19]. The crystal structure of the complex responsible of this color-change is known for $3 d$ ions [20-27], but this is only very recently that some of us managed to determine it for lanthanides from $\mathrm{Sm}^{\mathrm{III}}$ to $\mathrm{Lu}^{\mathrm{III}}[28,29]$. The obtained neutral $\mathrm{Ln}(\mathrm{L})_{3} \cdot \mathrm{xH}_{2} \mathrm{O}$ complexes were found to behave as single-molecule magnets (SMM) for $\mathrm{Ln}=\mathrm{Dy}$ [28] or $\mathrm{Yb}$ [29] (respectively DyMurex and YbMurex). For DyMurex, the original $\mathrm{N}_{3} \mathrm{O}_{6}$ environment of the Dy ${ }^{\mathrm{III}}$ ion permitted to demonstrate the crucial role played by the local symmetry of the oxygen surrounding over the nitrogen one. It shows also how the dipolar electrostatic field around the DyIII (and not the local charge) is the governing factor of its magnetic behavior [28]. For YbMurex, significant near-infrared (NIR) emissions have been 
observed that permitted to perform one of the first NIR magneto-luminescent correlations. It evidenced also that the contribution of the $\mathrm{Yb}^{\mathrm{III}}$ excited-states to the emissions have to be carefully considered in such procedures [29].<smiles>[NH3+][NH3+]</smiles>

Scheme 1. The murexide ligand (also known as ammonium salt of 2,6-dioxo-5-[(2,4,6-trioxo-5hexahydropyrimi-dinylidene)amino]-3H-pyrimidin-4-olate).

In this study, we have been able to obtain information on the crystal structure of two of the missing light lanthanide ions from the series $\left(\mathrm{Ln}=\mathrm{Ce}^{\mathrm{III}}\right.$ and $\left.\mathrm{Nd}^{\mathrm{III}}\right)$. Light lanthanide ions have so far drawn less attention than heavier ones in the field of molecular magnetism [30]. This is somewhat intriguing as most permanent magnets are made of $\mathrm{Nd}^{\mathrm{III}}$ or $\mathrm{Sm}^{\mathrm{III}}$ ions [31]. We report here the synthesis and magnetic properties of the Ce ${ }^{\mathrm{III}}$ (CeMurex) and $\mathrm{Nd}^{\mathrm{III}}$ derivatives (NdMurex). For the later a bifunctional compound was obtained as NIR emission was observed.

\section{Results}

\subsection{Crystal Structure}

NdMurex crystallizes in the triclinic system, $P-1$ space group $\left(\mathrm{n}^{\circ} 2\right.$, see Table $\left.\mathrm{S} 1\right)$. The asymmetric unit is made of one $\mathrm{Nd}^{\mathrm{III}}$ ion coordinated by two murexide ligands and three water molecules. The murexide ligand acts a tri-dentate ligand and a capped $\mathrm{N}_{2} \mathrm{O}_{7}$ coordination environment around the $\mathrm{Nd}^{\mathrm{III}}$ ion formed. $\mathrm{Nd}-\mathrm{O}$ and $\mathrm{Nd}-\mathrm{N}$ distances are in the $2.42 \AA-2.67 \AA$ and $2.74 \AA-2.86 \AA$ range, respectively (Table S2). SHAPE analysis revealed that the coordination polyhedron was either a distorted capped square antiprism $\left(\mathrm{C}_{4 \mathrm{v}}\right)$ or a spherical capped square antiprism $\left(\mathrm{C}_{4 \mathrm{~d}}\right)$ (Figure 1 , Table S3) [32,33]. One free murexide ligand ensures the electroneutrality of the asymmetric unit and seven uncoordinated water molecules were found. An inversion center located close to one of the two murexide ligands creates a dimeric structure [34] with Nd-Nd distance of $7.55 \AA$ (see Figures 1 and 2, Figures S1-S3) and fourteen water molecules in the intermolecular space. The overall formula of NdMurex is then $\left[\mathrm{Nd}_{2}(\mathrm{~L})_{4}\left(\mathrm{H}_{2} \mathrm{O}\right)_{6}\right](\mathrm{L})_{2}\left(\mathrm{H}_{2} \mathrm{O}\right)_{14}$ (Figure 1). The shortest intermolecular Nd-Nd distance is $9.58 \AA$.

It is interesting to compare this compound with the ones obtained with heavier lanthanide ions ( $\mathrm{Ln}=\mathrm{Sm}$ to Lu), such as DyMurex [28] and YbMurex [29] where neutral monomeric complex of formula $\mathrm{Ln}(\mathrm{L})_{3} \cdot \mathrm{xH}_{2} \mathrm{O}$ where formed. The striking originality in NdMurex is the ability of the murexide ligand to bind two different $\mathrm{Nd}^{\mathrm{III}}$ ions either via its tris-dentate clamp but also via one of the two external carbonyl group that were left uncoordinated in the case of $\mathrm{Ln}(\mathrm{L})_{3} \cdot \mathrm{xH}_{2} \mathrm{O}$. This extra coordination is made via the longest $\mathrm{Nd}-\mathrm{O}$ distance $(\mathrm{Nd}-\mathrm{O} 6=2.67 \AA)$ and is stabilized via strong stacking between two symmetry-related murexide ligand (Figure 2). It is likely that the ionic size of the lanthanide ion is the governing factor in stabilizing the dimeric crystalline structure over the monomeric one. 


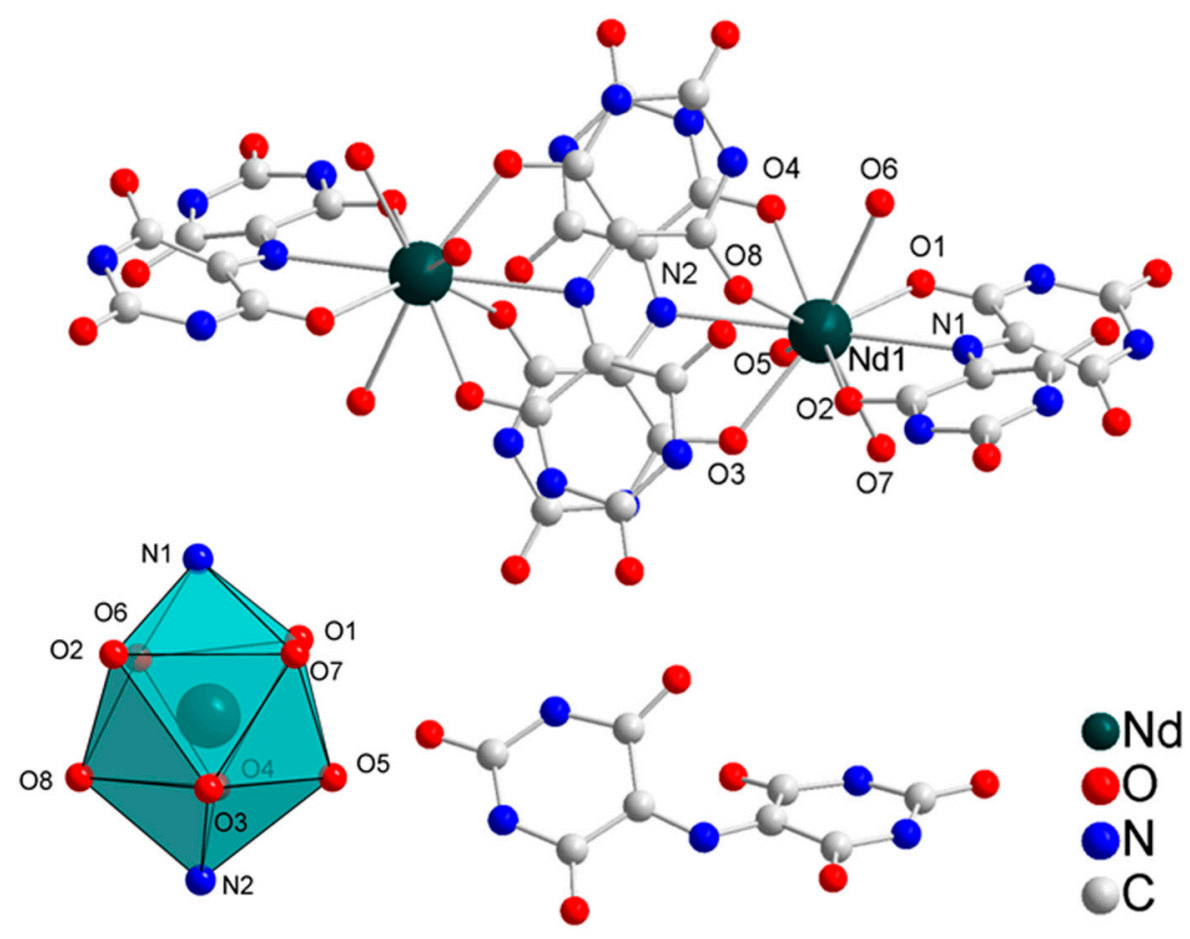

Figure 1. The best view of NdMurex with one of the two free murexide molecules and labeling scheme. Inset view of the $\mathrm{Nd} 1$ coordination polyhedron. Hydrogen atoms and water molecules are omitted for clarity.
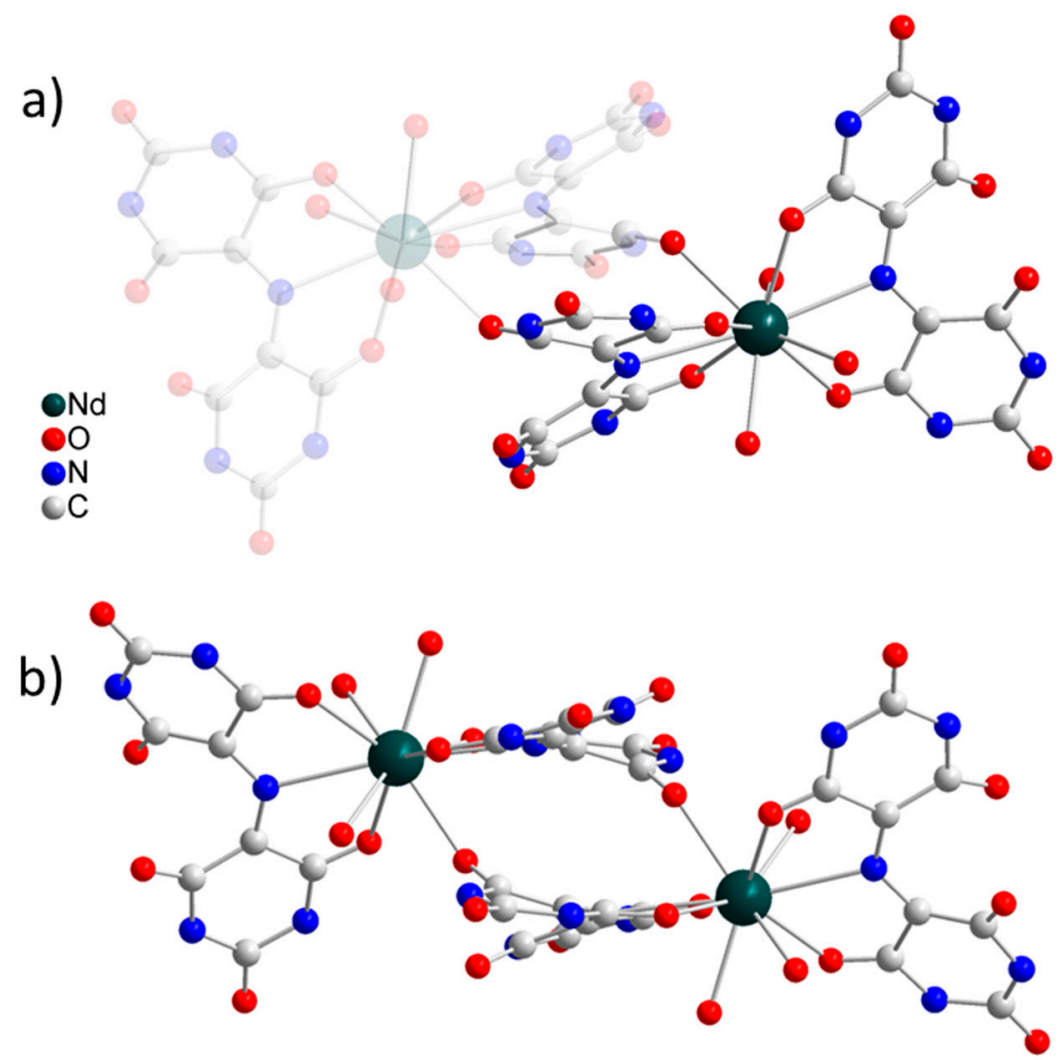

Figure 2. Best views of the NdMurex dimeric structure with (a) the asymmetric unit highlighted, and (b) a view parallel to the stacking of murexide ligands. Hydrogen atoms and water molecules are omitted for clarity. 


\subsection{Thermal Stability}

The purple crystals of NdMurex are stable for some hours out of their mother solution. Then, cracks appear on the crystal's surfaces associated with the loss of crystallization water molecules. This has been confirmed by thermogravimetric analysis (TGA/DTA) where $18 \%$ weight loss, compatible with the loss of 14 water molecules, was observed between 20 and $200{ }^{\circ} \mathrm{C}$ (Figure 3). The anhydrous derivative formed, named NdMurexAnhy, was stable up to $300^{\circ} \mathrm{C}$. Similar dehydration was observed for an overnight room-temperature drying of NdMurex crystals. A crystalline powder was obtained and powder X-ray diffraction evidenced a clear phase transition upon dehydration (Figure S4). The Ce $\mathrm{e}^{\mathrm{III}}$ derivative was obtained only as this anhydrous form named CeMurexAnhy and was isostructural to NdMurexAnhy (Figure S4).

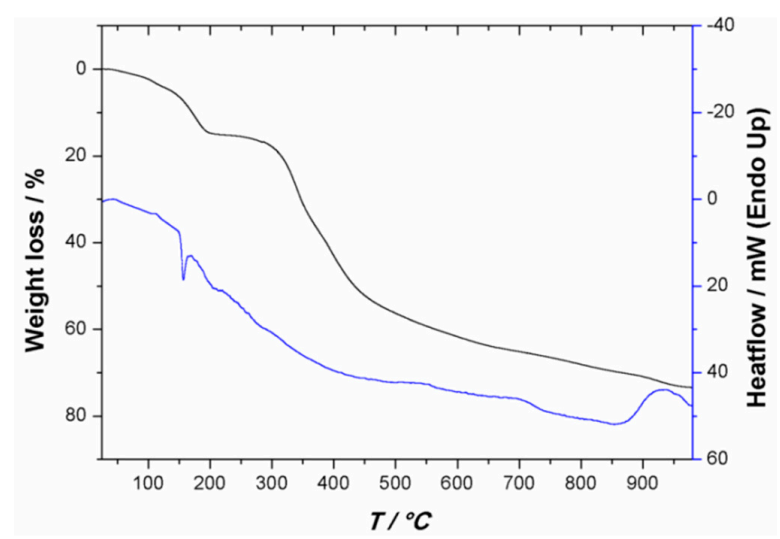

Figure 3. Thermogravimetric (right axis) and thermodifferential (left axis) analysis of NdMurex performed under $\mathrm{N}_{2}$ atmosphere.

\subsection{Magnetic Characterization}

Static magnetic measurements of NdMurex have been performed at 1000 Oe on fresh crystals crushed into teflon pellets. The room temperature $\chi_{\mathrm{M}} \mathrm{T}$ value was $3.16 \mathrm{emu} \cdot \mathrm{K} \cdot \mathrm{mol}^{-1}$ in good agreement with the theoretical value expected for two isolated $\mathrm{Nd}^{\mathrm{III}}$ ion $\left({ }^{4} \mathrm{I}_{9 / 2}, g_{J}=8 / 11, J=9 / 2, \mathrm{X}_{\mathrm{M}} \mathrm{T}_{300 \mathrm{~K}}=\right.$ $\left.2 \times 1.64 \mathrm{emu} \cdot \mathrm{K} \cdot \mathrm{mol}^{-1}\right)$. This confirms that most of crystallization water molecules were retained at this point (all crystallization water molecules considered in NdMurex molecular weight). As the temperature was lowered, $\chi_{\mathrm{M}} \mathrm{T}$ decreased to reach $1.11 \mathrm{emu} \cdot \mathrm{K} \cdot \mathrm{mol}^{-1}$ at $2 \mathrm{~K}$ (Figure 4). This decrease was attributed to a standard depopulation of $\mathrm{Nd}^{\mathrm{III}}$ Stark's sub-levels as long intra- and intermolecular distances preclude the occurrence of $\mathrm{Nd}-\mathrm{Nd}$ magnetic interactions.

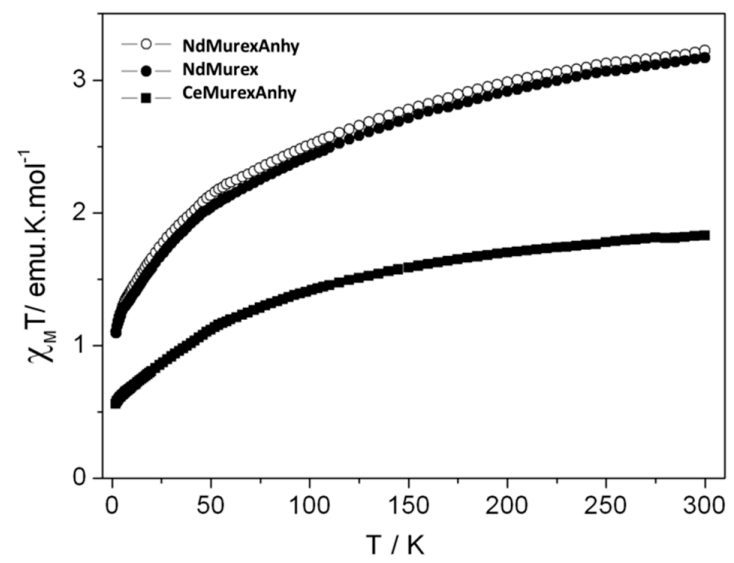

Figure 4. Temperature dependence of $\chi_{M} T$ for NdMurex, NdMurexAnhy, and CeMurexAnhy measured with $\mathrm{H}_{\mathrm{dc}}=1000$ Oe. 
A pellet of overnight dried NdMurexAnhy was measured and the room temperature $\chi_{M}{ }^{T}$ value was $3.22 \mathrm{emu} \cdot \mathrm{K} \cdot \mathrm{mol}^{-1}$. Temperature dependence of its magnetic behavior was then highly similar to the one of NdMurex (Figure 4). Same procedures were used with CeMurexAnhy with a room temperature $\chi_{\mathrm{M}} \mathrm{T}$ value of $1.82 \mathrm{emu} \cdot \mathrm{K} \cdot \mathrm{mol}^{-1}$ in agreement with the expected value $\left({ }^{2} \mathrm{~F}_{5 / 2}, g_{J}=6 / 7\right.$, $J=5 / 2, \chi_{\mathrm{M}} \mathrm{T}_{300 \mathrm{~K}}=2 \times 0.80 \mathrm{emu} \cdot \mathrm{K} \cdot \mathrm{mol}^{-1}$ ) (Figure 4$)$.

Dynamic magnetic measurements were performed on NdMurex and NdMurexAnhy and the optimum external $\mathrm{H}_{\mathrm{dc}}$ field to observe magnetic slow relaxation was found to be 1200 Oe (Figures S5 and S6). For both samples, frequency dependence of the out-of-phase susceptibility was observed in the 1.8-4.4 K region (Figure 5 and Figure S7). The temperature dependence of the relaxation was found to be close to a linear regime and was estimated considering an Orbach relaxation where $\tau=$ $\tau_{0} \exp \left(-\mathrm{U}_{\text {eff }} / \mathrm{k}_{\mathrm{B}} \mathrm{T}\right)$ with $\tau_{0}$ the characteristic relaxation time and $\mathrm{U}_{\mathrm{eff}}$ the energy barrier for spin reversal. On both samples, very small variations were observed, and $U_{\text {eff }}$ almost identical $\left(U_{\text {eff }}=6.20(0.80) \mathrm{K}\right.$, $4.31 \mathrm{~cm}^{-1}\left(\tau_{0}=2.20(0.92) \times 10^{-5} \mathrm{~s}\right)$ and $U_{\text {eff }}=6.25(0.90) \mathrm{K}, 4.34 \mathrm{~cm}^{-1}\left(\tau_{0}=4.85(0.40) \times 10^{-5} \mathrm{~s}\right)$ for NdMurex and NdMurexAnhy respectively). Indeed, the dehydration of NdMurex impacts only, and in a moderate way, the characteristic relaxation time (Figures 6 and 7). On both samples the distribution of the relaxation times $\alpha$ was investigated using normalized Cole-Cole plots and an extended Debye equation (Figures 6 and 7). On both samples, stable $\alpha$ values around 0.2 were observed that indicate a moderate distribution of the relaxation times. Large relaxing fractions were observed with $\left(1-\chi_{\mathrm{S}} / \chi_{\mathrm{T}}\right)=91 \%$ and $80 \%$ at $2 \mathrm{~K}$ for NdMurex and NdMurexAnhy, respectively (with $\chi_{\mathrm{S}}$ = adiabatic susceptibility, $\chi_{\mathrm{T}}$ isothermal susceptibility, see Tables S4-S7). Overall, these behaviors highlight that the magnetic behavior of NdMurex was not sensitive to dehydration, and consequently that intermolecular interactions play a minor role in its magnetic slow relaxation.

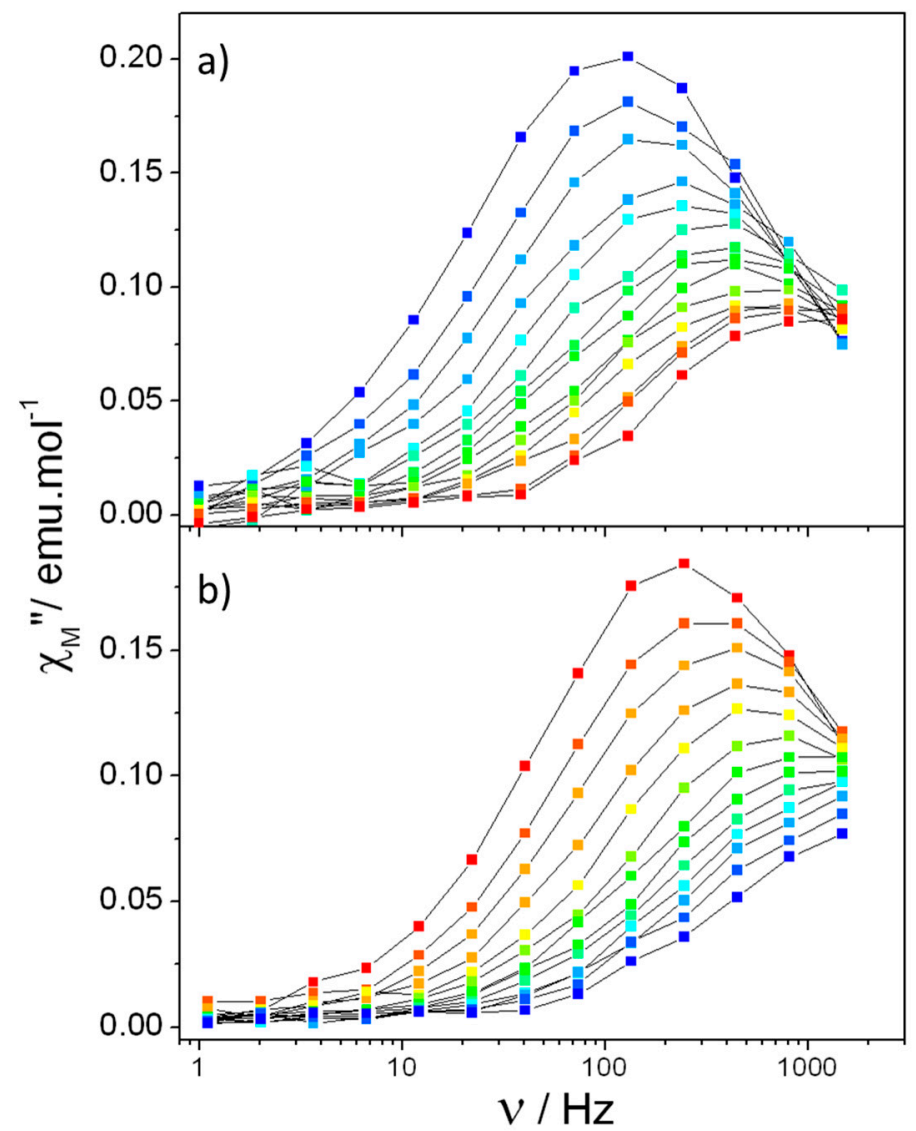

Figure 5. Frequency dependence of the out-of-phase susceptibility of NdMurex (a) and NdMurexAnhy (b) with $\mathrm{H}_{\mathrm{dc}}=1200$ Oe for temperatures from 1.8 (blue) to $4.4 \mathrm{~K}$ (red). Lines are guide to the eye. 

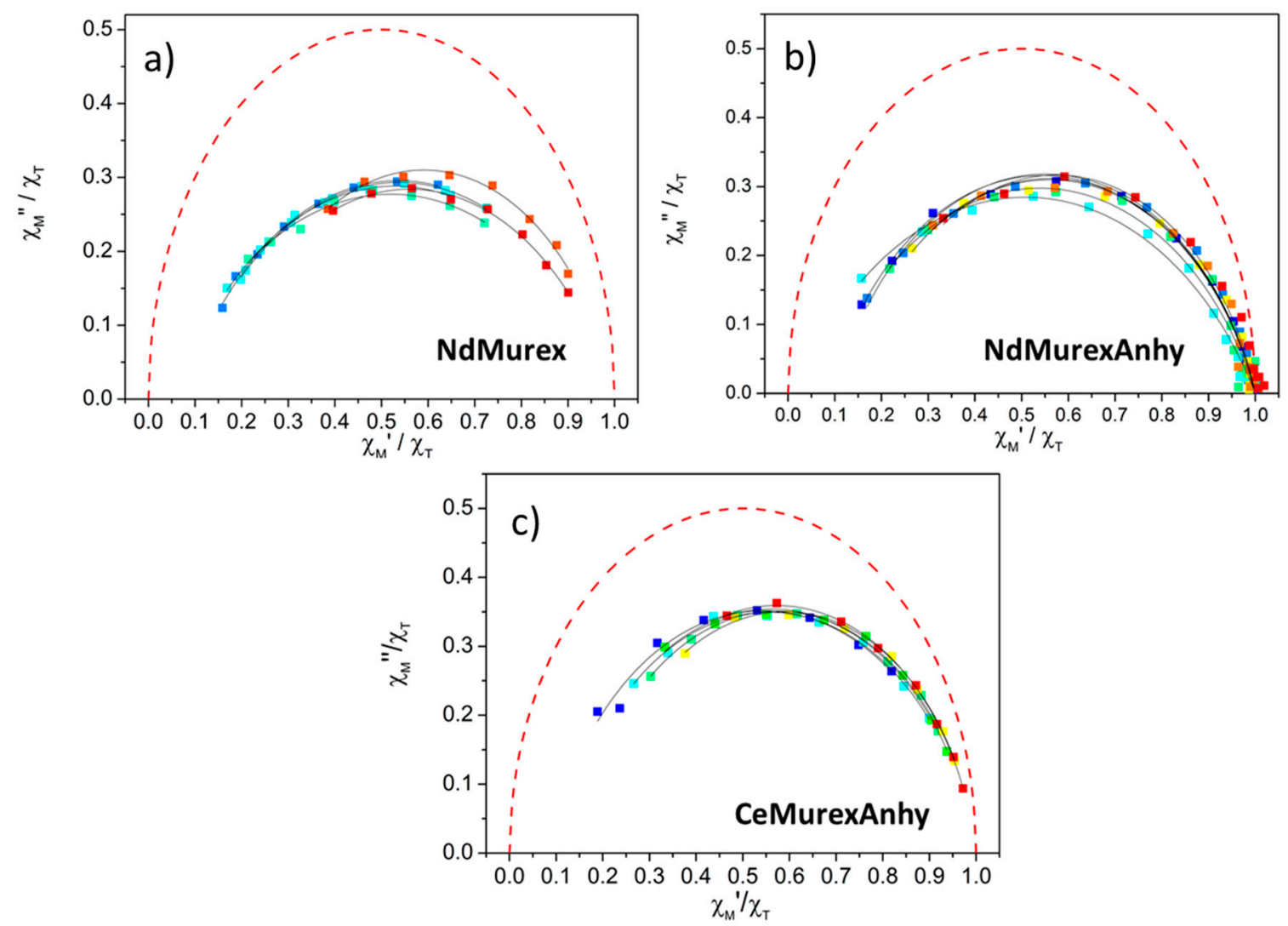

Figure 6. Cole-Cole plots measured for temperatures from 1.8 (blue) to $5 \mathrm{~K}$ (red) and for NdMurex $\left(\mathrm{H}_{\mathrm{dc}}=1200 \mathrm{Oe}, \mathbf{a}\right)$, NdMurexAnhy $\left(\mathrm{H}_{\mathrm{dc}}=1200 \mathrm{Oe}, \mathbf{b}\right)$, and CeMurexAnhy $\left(\mathrm{H}_{\mathrm{dc}}=400 \mathrm{Oe}, \mathbf{c}\right)$ with selected fits and simulation of the ideal distribution of the magnetic relaxation as red curve.

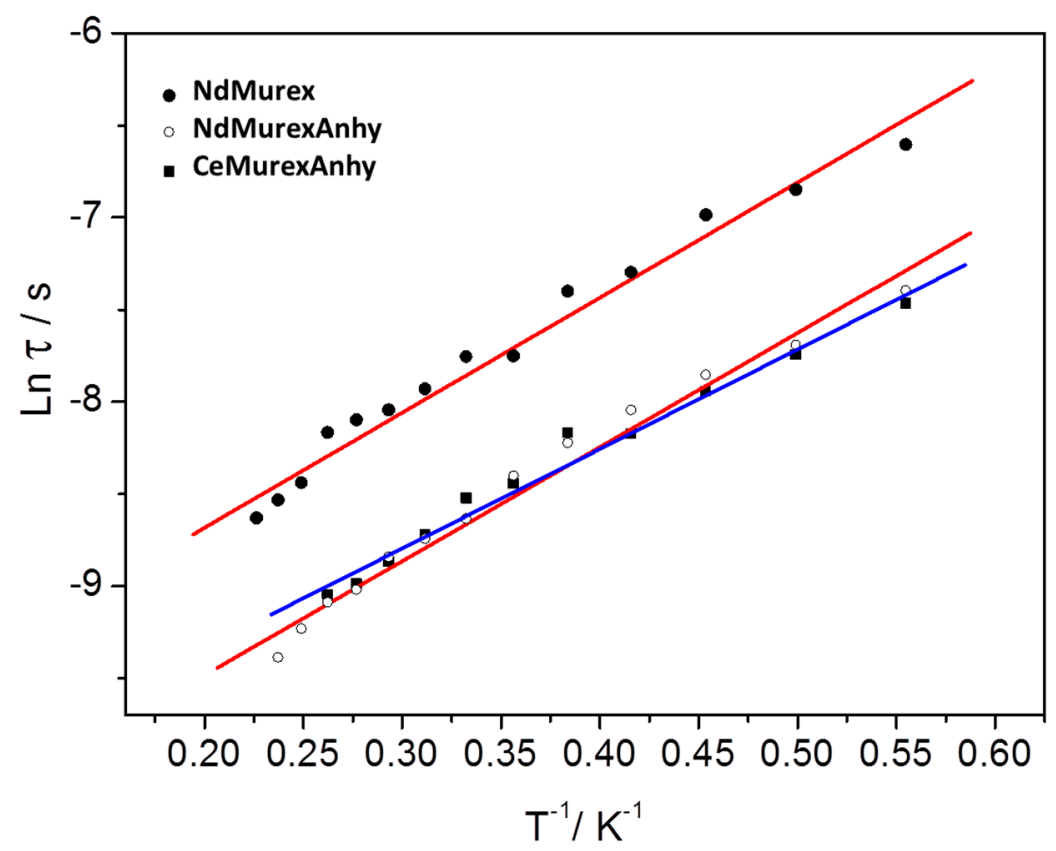

Figure 7. Arrhenius plot with best fits for NdMurex (full circles), NdMurexAnhy (empty circles), and CemurexAnhy (full squares).

The cerium derivative, CeMurexAnhy, has been was measured with an optimum external $\mathrm{H}_{\mathrm{dc}}$ field of 400 Oe (Figure S8). Frequency dependence of the out-of-phase susceptibility was observed between $1.8 \mathrm{~K}$ and $4 \mathrm{~K}$ (Figure S9). The magnetic relaxation was also governed by Orbach process 
with $\mathrm{U}_{\text {eff }}=5.40(0.75) \mathrm{K}, 3.75 \mathrm{~cm}^{-1}$ and $\tau_{0}=3.02(1.10) \times 10^{-5} \mathrm{~s}$ (Figure 7$)$. As for the $\mathrm{Nd}^{\mathrm{III}}$ derivatives, stable $\alpha$ values around 0.15 were observed, with 92\% relaxing fraction at $2 \mathrm{~K}$ (Figure 6, Tables S8 and S9).

All three samples were rare examples of SMMs that involved light lanthanide ions [30]. Whereas several Ce $\mathrm{e}^{\mathrm{III}}$-based SMMs have been reported [30,35-40], only few examples of Nd ${ }^{\mathrm{III}}-\mathrm{SMMs}$ are known. We will detail them here.

The first report of an $\mathrm{Nd}-\mathrm{SMM}$ was a $\mathrm{Nd}^{\mathrm{III}}$ with a full nitrogen environment $\mathrm{N}_{9}$ with an almost perfect $D_{3 h}$ symmetry, but its effective energy barrier was low $\left(\mathrm{U}_{\mathrm{eff}}=2.8 \mathrm{~cm}^{-1}\right)$ (Table 1$)$ [41]. Other examples on sandwich complexes from the COT family (COT = bis(trimethylsilyl)cyclooctatetraenyl dianion) where the $\mathrm{Nd}^{\mathrm{III}}$ was in $\mathrm{C}_{16}$ environment shows $\mathrm{SMM}$ behavior $\left(\mathrm{U}_{\text {eff }}=14.6 \mathrm{~cm}^{-1}\right)$ [39]. Another organometallic $\mathrm{Nd}^{\mathrm{III}} \mathrm{SMM}$ was reported with $\mathrm{Cp}^{*}$ as main ligands $\left(\mathrm{U}_{\mathrm{eff}}=29 \mathrm{~cm}^{-1}\right)$ [42]. Macrocyclic complexes of $\mathrm{Nd}^{\mathrm{III}}$ ions show mixed magnetic relaxation processes in which $\mathrm{U}_{\mathrm{eff}} \approx 21 \mathrm{~cm}^{-1}$ or $\mathrm{U}_{\mathrm{eff}} \approx 51 \mathrm{~cm}^{-1}$ depending on the crown-ether that is considered $\left(\mathrm{O}_{12}\right.$ or $\mathrm{O}_{10} \mathrm{~N}_{2}$ environment) [37]. Cadmium-based metalacrowns stabilize hexagonal bipyramidal environment $\left(\mathrm{O}_{8}\right)$ for $\mathrm{Nd}$ III ions with $\mathrm{U}_{\text {eff }} \approx 15 \mathrm{~cm}^{-1}$ but strong influence of Raman-like relaxation process was observed [40]. $\mathrm{Nd}^{\mathrm{III}}$ derivatives from the polyoxometallates family have also been studied and energy barriers of $\mathrm{U}_{\text {eff }}=51.4 \mathrm{~cm}^{-1}$ [43] and $\mathrm{U}_{\text {eff }}=34 \mathrm{~cm}^{-1}$ [44] were reported. A detailed study [35] of the magnetic anisotropy of complexes with light lanthanide ions highlights that Ising-type anisotropy can be found in the well-known $\mathrm{N}_{2} \mathrm{O}_{6}$ environment that is very common for Dy-based SMMs and $\mathrm{U}_{\text {eff }} \approx 20 \mathrm{~cm}^{-1}$ for the $\mathrm{Nd}^{\mathrm{III}}$ derivative is reported.

Table 1. Table of Nd ${ }^{\mathrm{III}}$-based Single-Molecule Magnets with $\mathrm{U}_{\text {eff }}$ values and references associated.

\begin{tabular}{|c|c|c|c|}
\hline Compound & $\mathbf{H}_{\mathrm{dc}}$ & $\mathrm{U}_{\mathrm{eff}}\left(\mathrm{cm}^{-1}\right)$ & Reference \\
\hline $\mathrm{NdTp}_{3}$ & 100 & 2.8 & [41] \\
\hline $\left.\mathrm{Li}(\mathrm{DME})_{3}\right]\left[\mathrm{Nd}\left(\mathrm{COT}^{\prime \prime}\right)_{2}\right]$ & 1000 & 15 & [39] \\
\hline$\left[\mathrm{Nd}\left(\mathrm{NO}_{3}\right)_{3}(18\right.$-crown-6)] & 1000 & 21 & [37] \\
\hline$\left[\mathrm{Nd}\left(\mathrm{NO}_{3}\right)_{3}(1,10\right.$-diaza-18-crown-6)] & 1000 & 51 & [37] \\
\hline$\left[\mathrm{NdCd}_{3}(\mathrm{Hquinha})_{3}\left(n-\mathrm{Bu}_{3} \mathrm{PO}\right)_{2} \mathrm{I}_{3}\right] \cdot 3 \mathrm{EtOH} \cdot 2 \mathrm{H}_{2} \mathrm{O}$ & 1000 & 15 & [40] \\
\hline$\left[\mathrm{Nd}\left(\mathrm{W}_{5} \mathrm{O}_{18}\right)_{2}\right]^{--}$ & 1000 & 51 & {$[43]$} \\
\hline $\mathrm{Nd}_{2}(2-\mathrm{FBz})^{4-}\left(\mathrm{NO}_{3}\right)_{2}(\text { phen })_{2}$ & 1500 & 9.5 & [45] \\
\hline $\mathrm{Nd}(\mathrm{fdh})_{3}(\mathrm{bpy})$ & 500 & 20 & [35] \\
\hline$\left\{\left[\mathrm{Nd}\left(\mu_{2}-\mathrm{L} 1\right)_{3} \cdot\left(\mathrm{H}_{2} \mathrm{O}\right)_{2}\right] \cdot \mathrm{H}_{2} \mathrm{O}\right\}_{\mathrm{n}}$ & 2000 & 19.5 & [36] \\
\hline$\left[\mathrm{Nd}\left(\mu_{2}-\mathrm{L} 2\right)_{2} \cdot\left(\mathrm{CH}_{3} \mathrm{COO}\right) \cdot\left(\mathrm{H}_{2} \mathrm{O}\right)_{2}\right]_{\mathrm{n}}$ & 2000 & 14 & [36] \\
\hline $\mathrm{Nd}_{2}\left(\mu_{2}-9-\mathrm{AC}\right)_{4}(9-\mathrm{AC})_{2}(\mathrm{bpy})_{2}$ & 2000 & 8 & [46] \\
\hline$\left\{\left[\mathrm{Nd}_{2}\left(\mathrm{CNCH}_{2} \mathrm{COO}\right)_{6}\left(\mathrm{H}_{2} \mathrm{O}\right)_{4}\right] \cdot 2 \mathrm{H}_{2} \mathrm{O}\right\}_{\mathrm{n}}$ & 1500 & 19 & [47] \\
\hline$\left.\left[\mathrm{Nd}\left(\mu_{2}-\mathrm{L} 1\right)_{3}\left(\mathrm{H}_{2} \mathrm{O}\right)_{2}\right] \cdot \mathrm{C}_{2} \mathrm{H}_{3} \mathrm{~N}\right\}_{\mathrm{n}}$ & 2000 & 19 & [48] \\
\hline$\left[\mathrm{Nd}\left(\mu_{2}-\mathrm{L}_{2}\right)\left(\mathrm{L}_{2}\right)\left(\mathrm{CH}_{3} \mathrm{COO}\right)\left(\mathrm{H}_{2} \mathrm{O}\right)_{2}\right]_{\mathrm{n}}$ & 3500 & 15 & [48] \\
\hline$\left(\mathrm{NH}_{2} \mathrm{Me}_{2}\right)_{3}\left\{\left[\mathrm{Nd}\left(\mathrm{Mo}_{4} \mathrm{O}_{13}\right)(\mathrm{DMF})_{4}\right]_{3}(\mathrm{BTC})_{2}\right\} \cdot 8 \mathrm{DMF}$ & 500 & 34 & [44] \\
\hline $\mathrm{Cp}^{*}{ }_{2} \mathrm{Nd}\left(\mathrm{BPh}_{4}\right)$ & 1000 & 29 & [42] \\
\hline$\left[\mathrm{Nd}(\mathrm{CyPh} 2 \mathrm{PO}) 2\left(\mathrm{H}_{2} \mathrm{O}\right) 5\right] \mathrm{I} 3 \cdot 2(\mathrm{CyPh} 2 \mathrm{PO}) \cdot 3 \mathrm{EtOH}$ & 0 & n.a. * & [49] \\
\hline$\left\{\left[\mathrm{tBuPO}\left(\mathrm{NH}^{\mathrm{i}} \mathrm{Pr}\right)_{2} \mathrm{Nd}\left(\mathrm{H}_{2} \mathrm{O}\right)_{5}\right]-[\mathrm{I}]_{3} \cdot \mathrm{tBuPO}\left(\mathrm{NH}^{\mathrm{i}} \mathrm{Pr}\right)_{2} \cdot\left(\mathrm{H}_{2} \mathrm{O}\right)\right\}$ & 0 & $11 / 17$ & {$[50]$} \\
\hline 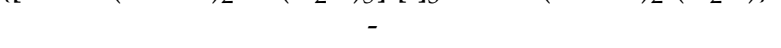 & 1000 & 27 & {$[50]$} \\
\hline- & 2000 & n.a. ** & [49] \\
\hline NdMurex & 1200 & 4.3 & This study \\
\hline NdMurexAnhy & 1200 & 4.3 & This study \\
\hline CeMurexAnhy & 400 & 3.75 & This study \\
\hline
\end{tabular}

$\mathrm{Tp}^{-}=$trispyrazolylborate, $\mathrm{COT}^{\prime \prime}=$ bis(trimethylsilyl)cyclooctatetraenyl dianion, $\mathrm{H}_{2}$ quinha = quinaldichydroxamic acid, $\mathrm{DME}=$ dimethoxyethane, $\mathrm{FBz}=2$-fluorobenzoate, phen $=$ phenantroline, $\mathrm{fdh}=1,1,1$-fluoro-5,5dimethyl-hexa-2,4-dione, bpy $=2,2^{\prime}$-bipyridine, L1 $=3,5$-dinitrobenzoate, L2 $=2$,4-dinitrobenzoate, BTC $=$ 1,3,5-benzenetricarboxylate), $\left[\mathrm{Cp}^{*}\right]^{-}$pentamethylcyclopentadienyl anion, 9-AC $=$anthracenecarboxylate, bpy $=2,2^{\prime}$-bipyridine, $\mathrm{CyPh}_{2} \mathrm{PO}=$ cyclohexyl(diphenyl)phosphine oxide). ${ }^{*}$ Dual Raman and quantum tunneling processes observed with no evidence of Orbach magnetic relaxation; ** Original report has been revised in the cited reference for one with no evidence of Orbach magnetic relaxation.

To the best of our knowledge only two polynuclear Nd-SMMs (dimers in these cases) have been reported. The first one is made of 2-fluorobenzoate ligands that bridges two phenantroline-chelated 
$\mathrm{Nd}^{\mathrm{III}}$ ions [45]. The $\mathrm{N}_{2} \mathrm{O}_{8}$ environment that is created, induces a mixed Orbach and Raman-like relaxation with $\mathrm{U}_{\mathrm{eff}}=9.5 \mathrm{~cm}^{-1}$. Nd $\mathrm{NI}^{\mathrm{III}}$ luminescence is observed but no magneto-luminescent correlation has been possible. On the contrary, such correlation has been possible on the second example [46] that is a carboxylate-bridged dimer with terminal bipyridine ligands $\left(\mathrm{N}_{2} \mathrm{O}_{7}\right.$ environment, mixed Orbach and Raman-like relaxation with $U_{\text {eff }}=8 \mathrm{~cm}^{-1}$ ). The splitting of the lowest five Stark levels of the $\mathrm{J}=9 / 2$ state of the ${ }^{4} \mathrm{I}_{9 / 2}$ level is clearly visible. The separation between the ground and first excited $\mathrm{m}_{\mathrm{J}}$ state is significantly bigger than $U_{\text {eff }}$ and confirms the presence of a mixed Orbach and Raman relaxation.

Several one-dimensional compounds made of $\mathrm{Nd}^{\mathrm{III}}$ display SMM behavior. These are onedimensional assembly of $\mathrm{Nd}^{\mathrm{III}}$ in $\mathrm{O}_{9}$ environment $\left(\mathrm{U}_{\mathrm{eff}}=18.8 \mathrm{~cm}^{-1}\right)$ [47] or benzene carboxylate-based chains with $\mathrm{Nd}^{\mathrm{III}}$ in $\mathrm{O}_{8}$ environment that shows mixed Orbach and Raman relaxation processes and $\mathrm{U}_{\text {eff }}$ values in the $18-21 \mathrm{~cm}^{-1}$ range $[36,48]$.

It is interesting to note that all these examples have been measured using an external static field $\mathrm{H}_{\mathrm{dc}}$ that ranges from $100 \mathrm{Oe}$ to $3500 \mathrm{Oe}$. The only examples of zero-field Nd-SMMs reported so far are based on complexes made of phosphonic diamide- or phosphine oxide-based ligands [49,50]. The extremely strong geometric constrain [51] imposed by the ligands around the $\mathrm{Nd}^{\mathrm{III}}$ ions imposes a highly symmetric $D_{5 h}$ pentagonal bipyramid environment $\left(\mathrm{O}_{7}\right)$ with the apical oxygen atoms from the phosphine groups closer of the $\mathrm{Nd}^{\mathrm{III}}$ ions than the five equatorial water molecules. This induces a suitable electrostatic surrounding of the $\mathrm{Nd}^{\mathrm{III}}$ ion that is an oblate ion [52]. However the nature of the magnetic relaxation in these two compounds is debated as the initial Orbach mechanisms identified in the first report $\left(\mathrm{U}_{\mathrm{eff}}=17.2 \mathrm{~cm}^{-1}\right)$ [50] has been revised to pure Raman or mixed Raman and QTM processes with no evidence of Orbach magnetic relaxation [49]. It can be noted that some examples may also be considered as relaxing via field-induced paramagnetism and not via standard SMM relaxation pathways. We cannot totally discard this possibility for the three samples we report here.

Last, it is worth noting that $U_{\text {eff }}$ values have always been found significantly lower than ab-initio energy gaps when available. Such discrepancy is also visible when magneto-luminescence correlations have been targeted [41]. The most striking example is found on the previously cited trispyrazolylborate-based Nd-SMM where $U_{\text {eff }}=2.8 \mathrm{~cm}^{-1}$ is observed while a $115 \mathrm{~cm}^{-1}$ energy gap is extrapolated from low-temperature absorption measurements. This indicates that under-barrier fast magnetic relaxation mechanisms can bevery efficient on Nd-SMMs.

\subsection{Luminescence Measurements}

The investigation of the luminescent properties of Ln-SMM [53] is now a common procedure to establish magneto-luminescent correlations [54]. However these have been mainly performed on $\mathrm{Tb}^{\mathrm{III}}$ and $\mathrm{Dy}{ }^{\mathrm{III}}$ ions because of their efficient SMM behaviors coupled with good emission properties (see ref [54] for full review) [55-59]. The approach has been less developed on NIR emissive Ln-SMM where mainly Er ${ }^{\mathrm{III}}-\mathrm{SMM}$ [60-65] and $\mathrm{Yb}^{\mathrm{III}}-\mathrm{SMM}$ [29,66-73] have been investigated. The drawback of these ions is that their emission is not always strong enough to allow for reliable magneto-luminescent correlations.

In this study, we have measured the luminescence properties of NdMurexAnhy as NdMurex is not suitable for NIR emission because of its numerous crystallization water molecules (Figure 8). At room temperature no emission has been detected, once again the remaining three coordination water molecules are very likely to quench $\mathrm{Nd}^{\mathrm{III}}$ emission. At $77 \mathrm{~K}$ and under $\lambda_{\text {exc }}=629 \mathrm{~nm}(f-f$ sensitization $)$ the broad and weak ${ }^{4} \mathrm{~F}_{3 / 2} \rightarrow{ }^{4} \mathrm{I}_{9 / 2}$ transition centered on $870 \mathrm{~nm}$ is observed together with the characteristic ${ }^{4} \mathrm{~F}_{3 / 2} \rightarrow{ }^{4} \mathrm{I}_{11 / 2}$ transition at $1050 \mathrm{~nm}$. For this emission peak, it has not been possible to deconvoluate the different crystal-field contributions of the Stark sub-levels. NdMurexAnhy is thus a NIR-emissive SMM where no magneto- luminescent correlations can be performed [54]. 


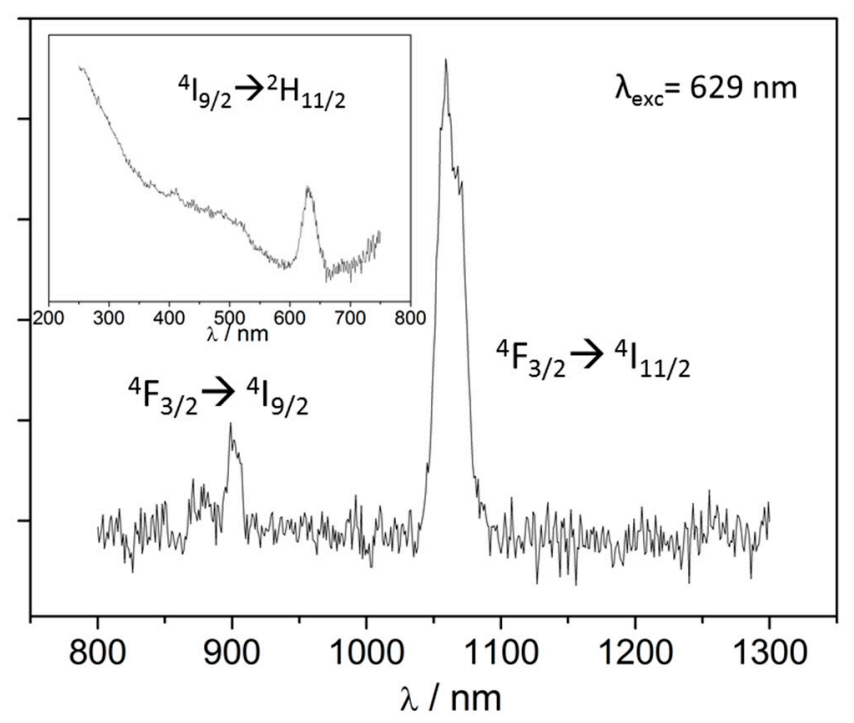

Figure 8. Emission spectrum of NdMurexAnhy measured at $77 \mathrm{~K}$ (excitation spectrum in inset).

\section{Materials and Methods}

\subsection{General Procedures and Methods}

All chemicals and reagents were of reagent grade (TCI chemicals) and used without further purification. Powder X-ray diffraction patterns were measured with a Panalytical X-Pert Pro diffractometer equipped with an $X^{\prime}$ celerator detector. Recording condition were $45 \mathrm{kV}, 45 \mathrm{~mA}$ with $\mathrm{Cu} \mathrm{K}_{\alpha}(\lambda=1.542 \AA)$ in $\theta-\theta$ mode. Simulated patterns from $X$-ray crystal structure have been obtained with Mercury 3.0 from CCDC. Thermogravimetric and thermodifferential analyses were performed under nitrogen atmosphere (heating rate $5{ }^{\circ} \mathrm{C} / \mathrm{min}$ ) with a PerkinElmer Pyris-Diamond thermal analyzer. Magnetic measurements were performed with a quantum design Magnetic properties Measurement System (MPMS) magnetometer on Teflon pellets. Diamagnetic corrections were applied using Pascal's constants [74]. Luminescence measurements performed using a Horiba-Jobin-Yvon Florolog-3 spectrometer equipped with a $450 \mathrm{~W}$ Xe lamp and an infrared photodiode cooled by nitrogen liquid (InGaAs, sensitivity 800-1600 nm). Recording conditions were $\mathrm{T}=77 \mathrm{~K}$, integration time $300 \mathrm{~ms}$ (10 accumulation ) for excitation spectrum and $\mathrm{T}=77 \mathrm{~K}$, integration time $300 \mathrm{~ms}$ (50 accumulation).

\subsection{Synthetic Procedure}

$0.1 \mathrm{mmol}$ of murexide (ammonium purpurate, " $\mathrm{NH}_{4} \mathrm{~L}$ ", $28.42 \mathrm{mg}$ ) was solubilized in $20 \mathrm{~mL}$ of water under strong stirring and a deep purple solution was obtained. $0.1 \mathrm{mmol}$ of $\mathrm{Nd}\left(\mathrm{NO}_{3}\right)_{3} \cdot 6 \mathrm{H}_{2} \mathrm{O}$ ( $45.78 \mathrm{mg}$ ) was dissolved in $2 \mathrm{~mL}$ of water and quickly added to the $\mathrm{NH}_{4} \mathrm{~L}$ solution. A color change was visible from dark to light purple after stirring for $5 \mathrm{~min}$. At that point, the solution was filtered on sintered glass $\mathrm{N}^{\circ} 3$ for some minutes and left undisturbed for one month at room temperature. Small prismatic purple crystals were then obtained. The $\mathrm{Ce}$ III derivative was obtained using a similar procedure but it was not possible to obtain X-ray quality single crystals. Therefore, only its anhydrous derivative was studied here. Elem anal. Calcd for NdMurex $\mathrm{C}_{48} \mathrm{H}_{64} \mathrm{~N}_{30} \mathrm{Nd}_{2} \mathrm{O}_{56}$ : C, 25.71; $\mathrm{H}, 2.88$; $\mathrm{N}, 18.75$. Found: $\mathrm{C}, 25.63, \mathrm{H}, 2.82 ; \mathrm{N}, 18.63$. Calcd for NdMurexAnhy $\mathrm{C}_{48} \mathrm{H}_{36} \mathrm{~N}_{30} \mathrm{Nd}_{2} \mathrm{O}_{42}$ : C, 28.97; $\mathrm{H}, 1.83$; N, 21.13. Found: $\mathrm{C}, 28.69, \mathrm{H}, 1.91 ; \mathrm{N}, 20.94$. Calcd for CeMurexAnhy $\mathrm{C}_{48} \mathrm{H}_{36} \mathrm{~N}_{30} \mathrm{Ce}_{2} \mathrm{O}_{42}: \mathrm{C}_{\text {, }}$ 29.03; H, 1.83; N, 21.17. Found: C, 28.71, H, 1.91; N, 20.96.

\subsection{Crystal Structure}

Crystals were mounted on a Bruker AXS diffractometer (APEXII) and crystal structures were collected at $150 \mathrm{~K}$ with $\mathrm{Mo} \mathrm{K}_{\alpha}(\lambda=0.71073 \AA)$ radiation. Data reduction and cell refinement were 
performed with Denzo and Scalepack [70,71]. Crystal structures were solved by SIR97 [72] and refined by SHELX97 [70] via WINGX [73] interface. Hydrogen atoms were located on ideal positions. Crystal data can be found free of charge from Cambridge Crystallographic Data Center (www.ccdc.cam.ac.uk/ data_request/cif) under reference (CCDC-1856342).

\section{Conclusions}

In this study, we report the synthesis and crystal structure of the light lanthanide adducts of the murexide ligand (" $\mathrm{NH}_{4} \mathrm{~L}$ "). Whereas lanthanide ions from Sm ${ }^{\mathrm{III}}$ to $\mathrm{Lu}^{\mathrm{III}}$ crystallize as mononuclear complexes of formula $\mathrm{Ln}(\mathrm{L})_{3} \cdot \mathrm{xH}_{2} \mathrm{O}$, for $\mathrm{Ln}=\mathrm{Nd}^{\mathrm{III}}$ dinuclear complexes of formula $\left[\mathrm{Nd}_{2}(\mathrm{~L})_{4}\left(\mathrm{H}_{2} \mathrm{O}\right)_{6}\right](\mathrm{L})_{2}\left(\mathrm{H}_{2} \mathrm{O}\right)_{14}$ are formed. Their dimeric nature is due to the original binding mode of the murexide ligand that involves not only its tri-dentate clamp but also one of its external carbonyl group to coordinate the $\mathrm{Nd}^{\mathrm{III}}$ ion. The obtained compounds show SMM behavior either in their hydrated (NdMurex: $\mathrm{U}_{\text {eff }}=6.20(0.80) \mathrm{K}, 4.31 \mathrm{~cm}^{-1} ; \tau_{0}=2.20 \times 10^{-5} \mathrm{~s}$ ) or anhydrous form $\left(\right.$ NdMurexAnhy: $\mathrm{U}_{\text {eff }}=6.25(0.90) \mathrm{K}, 4.34 \mathrm{~cm}^{-1} ; \tau_{0}=4.85 \times 10^{-5} \mathrm{~s}$; CeMurexAnhy: $\mathrm{U}_{\mathrm{eff}}=5.40(0.75)$ $\left.\mathrm{K}, 3.75 \mathrm{~cm}^{-1} ; \tau_{0}=3.02(1.10) \times 10^{-5} \mathrm{~s}\right)$. NdMurexAnhy is an NIR-emitting SMM. Each $\mathrm{Nd}^{\mathrm{III}}$ ion is coordinated by three water molecules whose substitution by terminal ligands may offer interesting possibilities for further optimization of the SMM behavior (tuning of the electrostatic surrounding) and NIR emission (removing of $\mathrm{OH}$ vibrators).

Supplementary Materials: The following are available online at http:/ / www.mdpi.com/2312-7481/4/4/44/s1, Table S1. Main crystallographic parameters for NdMurex. Table S2. Selected bond distance and angles of NdMurex. Table S3. Continuous Shape Measurements (CSM) extracted from analysis of NdMurex with SHAPE. Figure S1. Representation of the crystal packing of NdMurex along the $a$ axis. Water molecules and hydrogen atoms are omitted for clarity. Figure S2. Representation of the crystal packing of NdMurex along the $b$ axis. Water molecules and hydrogen atoms are omitted for clarity. Figure S3. Representation of the crystal packing of NdMurex along the $c$ axis. Water molecules and hydrogen atoms are omitted for clarity. Figure S4. Powder X-ray diffraction pattern for NdMurexAnhy and CeMurexAnhy measured at $300 \mathrm{~K}$ with simulation from the structural data file of NdMurex at $150 \mathrm{~K}$. Figure S5. Field dependence of the in-phase and out-of phase susceptibility measured at $2 \mathrm{~K}$ for NdMurex. Figure S6. Field dependence of the in-phase and out-of phase susceptibility measured at $2 \mathrm{~K}$ for NdMurexAnhy. Table S4. Table of the values extracted from the fitting of X" vs frequency curves for NdMurex. Table S5. Table of the values extracted from the Argand plot for NdMurex. Table S6. Table of the values extracted from the fitting of $X^{\prime \prime}$ vs. frequency curves for NdMurexAnhy. Table S7. Table of the values extracted from the Argand plot for NdMurexAnhy. Figure S7. Frequency dependence of the in-phase susceptibility of NdMurex and NdMurexAnhy with $\mathrm{H}_{\mathrm{dc}}=1200$ Oe for temperatures from 1.8 (blue) to $4.4 \mathrm{~K}$ (red). Lines are guide to the eye. Figure S8. Field dependence of the out-of phase susceptibility measured at $2 \mathrm{~K}$ for CeMurexAnhy. Figure S9. Frequency dependence of the in-phase (top) and out of phase susceptibility (bottom) measured with Hdc $=$ 400 Oe for CeMurex for temperatures from 1.8 (blue) to $5 \mathrm{~K}$ (red). Table S8. Table of the values extracted from the fitting of $X^{\prime \prime}$ vs. frequency curves for CeMurex. Table S9. Table of the values extracted from the Argand plot for CeMurex.

Author Contributions: Conceptualization, K.B. and O.G.; Methodology, K.B.; Investigation, K.B., G.H., S.F., Y.S., G.C., C.D.

Funding: This research is funded by Institut Universitaire de France (IUF).

Acknowledgments: T. Roisnel (CDifX) is acknowledged for help in crystal structure data collection. T. Guizouarn (Centre de Mesures Physiques, ISCR) is acknowledged for help in magnetic measurements.

Conflicts of Interest: The authors declare no conflict of interest.

\section{References}

1. Atwood, D. The Rare Earth Elements: Fundamentals and Applications; Wiley: Hoboken, NJ, USA, 2012.

2. Benelli, C.; Gatteschi, D. Introduction to Molecular Magnetism: From Transition Metals to Lanthanides; Wiley: Hoboken, NJ, USA, 2015.

3. Clérac, R.; Winpenny, R.E.P. 50 Years of Structure and Bonding-The Anniversary Volume; Mingos, D.M.P., Ed.; Springer International Publishing: Cham, Switzerland, 2016; p. 35.

4. Prša, K.; Nehrkorn, J.; Corbey, J.; Evans, W.; Demir, S.; Long, J.; Guidi, T.; Waldmann, O. Perspectives on Neutron Scattering in Lanthanide-Based Single-Molecule Magnets and a Case Study of the $\mathrm{Tb}_{2}\left(\mu-\mathrm{N}_{2}\right)$ System. Magnetochemistry 2016, 2, 45. [CrossRef] 
5. Eliseeva, S.V.; Bunzli, J.C.G. Rare earths: Jewels for functional materials of the future. New J. Chem. 2011, 35, 1165-1176. [CrossRef]

6. Bunzli, J.-C.G. Lanthanide Luminescence for Biomedical Analyses and Imaging. Chem. Rev. 2010, 110, 2729-2755. [CrossRef] [PubMed]

7. Bunzli, J.C.G. Lanthanide Luminescent Bioprobes (LLBs). Chem. Lett. 2009, 38, 104-109. [CrossRef]

8. Kido, J.; Okamoto, Y. Organo Lanthanide Metal Complexes for Electroluminescent Materials. Chem. Rev. 2002, 102, 2357-2368. [CrossRef] [PubMed]

9. Fernandez-Garcia, G.; Flores Gonzalez, J.; Ou-Yang, J.-K.; Saleh, N.; Pointillart, F.; Cador, O.; Guizouarn, T.; Totti, F.; Ouahab, L.; Crassous, J.; et al. Slow Magnetic Relaxation in Chiral Helicene-Based Coordination Complex of Dysprosium. Magnetochemistry 2017, 3, 2. [CrossRef]

10. Wada, H.; Ooka, S.; Iwasawa, D.; Hasegawa, M.; Kajiwara, T. Slow Magnetic Relaxation of Lanthanide(III) Complexes with a Helical Ligand. Magnetochemistry 2016, 2, 43. [CrossRef]

11. Binnemans, K. Lanthanide-Based Luminescent Hybrid Materials. Chem. Rev. 2009, 109, 4283. [CrossRef] [PubMed]

12. Mamontova, E.; Long, J.; Ferreira, R.; Botas, A.; Luneau, D.; Guari, Y.; Carlos, L.; Larionova, J. Magneto-Luminescence Correlation in the Textbook Dysprosium(III) Nitrate Single-Ion Magnet. Magnetochemistry 2016, 2, 41. [CrossRef]

13. Farger, P.; Leuvrey, C.; Gallart, M.; Gilliot, P.; Rogez, G.; Rabu, P.; Delahaye, E. Elaboration of Luminescent and Magnetic Hybrid Networks Based on Lanthanide Ions and Imidazolium Dicarboxylate Salts: Influence of the Synthesis Conditions. Magnetochemistry 2017, 3, 1. [CrossRef]

14. Davidson, D. Murexide and leucomurexide. J. Am. Chem. Soc. 1936, 58, 1821-1822. [CrossRef]

15. Davidson, D.; Epstein, E. The murexide question. J. Org. Chem. 1936, 1, 305-314. [CrossRef]

16. Kashanian, S.; Gholivand, M.B.; Madaeni, S.; Nikrahi, A.; Shamsipur, M. Spectrophotometric study of the complexation reactions between alkaline-earth cations and murexide in some non-aqueous solutions. Polyhedron 1988, 7, 1227-1230. [CrossRef]

17. Shamsipur, M.; Esmaeili, A.; Amini, M.K. Formation of cobalt, nickel and copper-complexes with murexide in ethanol water mixtures. Talanta 1989, 36, 1300-1302. [CrossRef]

18. Shamsipur, M.; Madaeni, S.; Kashanian, S. Spectrophotometric study of the alkali-metal murexide complexes in some non-aqueous solutions. Talanta 1989, 36, 773-776. [CrossRef]

19. Parham, H.S.; Shamsipur, M. Spectrophotometric study of some alkali and alkaline-earth cryptates in dimethylformamide solution using murexide as a metallochromic indicator. Polyhedron 1992, 11, 987-991. [CrossRef]

20. Favas, M.C.; Kepert, D.L.; White, A.H.; Willis, A.C. Structural studies in metal-purpurate complexes. 3. Crystal-structures of triaquapurpuratoiron(II) purpurate hexahydrate and tetra-aquapurpuratomanganese(II) purpurate hexahydrate-Stereochemistry of the [M(tridentate ligand)(unidentate ligand) 3 ] complexes. J. Chem. Soc. Dalton Trans. 1977, 1350-1362. [CrossRef]

21. Kepert, D.L.; White, A.H.; Willis, A.C. Structural studies in metal-purpurate complexes. 2. Crystal-structures of diaquabis (purpurato)-calcium and diaquabis(purpurato)-cadmium dihydrate-Stereochemistry of the $[\mathrm{M} \text { (tridentate ligand })_{2}$ (unidentate ligand $\left.)_{2}\right]$ complexes. J. Chem. Soc. Dalton Trans. 1977, 1342-1349. [CrossRef]

22. Martin, R.L.; White, A.H.; Willis, A.C. Structural studies in metal-purpurate complexes. 1. Crystal-structures of potassium purpurate trihydrate and ammonium purpurate monohydrate (murexide). J. Chem. Soc. Dalton Trans. 1977, 1336-1342. [CrossRef]

23. Raston, C.L.; White, A.H.; Willis, A.C. Structural studies in metal-purpurate complexes. 5. Crystal-structure of di-mu-aqua-tetrakis(purpurato)distrontium tridecahydrate. J. Chem. Soc. Dalton Trans. 1977, 1368-1372. [CrossRef]

24. Raston, C.L.; White, A.H.; Willis, A.C. Structural studies in metal-purpurate complexes. 8. Crystal-structure of triaquapurpuratocalcium nitrate dihydrate. J. Chem. Soc. Dalton Trans. 1977, 1381-1384. [CrossRef]

25. White, A.H.; Willis, A.C. Structural studies in metal-purpurate complexes. 4. Crystal-structures of aquabis(purpurato)lead(II) and aquabis(purpurato)lead(II) trihydrate. J. Chem. Soc. Dalton Trans. 1977, 1362-1368. [CrossRef] 
26. White, A.H.; Willis, A.C. Structural studies in metal-purpurate complexes. 6. Crystal-structures of bis(purpurato)-copper(II) and bis(purpurato)-zinc(II) hydrates. J. Chem. Soc. Dalton Trans. 1977, 1372-1377. [CrossRef]

27. White, A.H.; Willis, A.C. Structural studies in metal-purpurate complexes. 7. Crystal-structures of diaquanitratopurpurato-cobalt(II) and diaquanitratopurpurato-zinc(II) dihydrate. J. Chem. Soc. Dalton Trans. 1977, 1377-1381. [CrossRef]

28. Jung, J.; Yi, X.; Huang, G.; Calvez, G.; Daiguebonne, C.; Guillou, O.; Cador, O.; Caneschi, A.; Roisnel, T.; Le Guennic, B.; et al. Analysis of the electrostatics in DyIII single-molecule magnet: The case study of Dy(Murex)3. Dalton Trans. 2015, 44, 18270-18275. [CrossRef] [PubMed]

29. Yi, X.; Bernot, K.; Le Corre, V.; Calvez, G.; Pointillart, F.; Cador, O.; Le Guennic, B.; Jung, J.; Maury, O.; Placide, V.; et al. Unraveling the Crystal Structure of Lanthanide-Murexide Complexes: Use of an Ancient Complexometry Indicator as a Near-Infrared-Emitting Single-Ion Magnet. Chem. Eur. J. 2014, 20, 1569-1576. [CrossRef] [PubMed]

30. Pointillart, F.; Cador, O.; Le Guennic, B.; Ouahab, L. Uncommon lanthanide ions in purely $4 f$ Single Molecule Magnets. Coord. Chem. Rev. 2017, 346, 150-175. [CrossRef]

31. Jürgen Buschow, K.H. Materials Science and Technology; Wiley-VCH Verlag GmbH \& Co. KGaA: Weinheim, Germany, 2006.

32. Casanova, D.; Cirera, J.; Llunell, M.; Alemany, P.; Avnir, D.; Alvarez, S. Minimal Distortion Pathways in Polyhedral Rearrangements. J. Am. Chem. Soc. 2004, 126, 1755-1763. [CrossRef] [PubMed]

33. Alvarez, S. Polyhedra in (inorganic) chemistry. Dalton Trans. 2005, 2209-2233. [CrossRef] [PubMed]

34. Mylonas-Margaritis, I.; Mayans, J.; Sakellakou, S.-M.; Raptopoulou, C.P.; Psycharis, V.; Escuer, A.; Perlepes, S.P. Using the Singly Deprotonated Triethanolamine to Prepare Dinuclear Lanthanide(III) Complexes: Synthesis, Structural Characterization and Magnetic Studies. Magnetochemistry 2017, $3,5$. [CrossRef]

35. Xu, M.-X.; Meng, Y.-S.; Xiong, J.; Wang, B.-W.; Jiang, S.-D.; Gao, S. Magnetic anisotropy investigation on light lanthanide complexes. Dalton Trans. 2018, 47, 1966-1971. [CrossRef] [PubMed]

36. Jassal, A.K.; Sran, B.S.; Suffren, Y.; Bernot, K.; Pointillart, F.; Cador, O.; Hundal, G. Structural diversity and photo-physical and magnetic properties of dimeric to 1D polymeric coordination polymers of lighter lanthanide(III) dinitrobenzoates. Dalton Trans. 2018, 47, 4722-4732. [CrossRef] [PubMed]

37. Wada, H.; Ooka, S.; Yamamura, T.; Kajiwara, T. Light Lanthanide Complexes with Crown Ether and Its Aza Derivative Which Show Slow Magnetic Relaxation Behaviors. Inorg. Chem. 2017, 56, 147-155. [CrossRef] [PubMed]

38. Khelifa, A.B.; Belkhiria, M.S.; Huang, G.; Freslon, S.; Guillou, O.; Bernot, K. Single-molecule magnet behaviour in polynuclear assembly of trivalent cerium ions with polyoxomolybdates. Dalton Trans. 2015, 44, 16458-16464. [CrossRef] [PubMed]

39. Le Roy, J.J.; Gorelsky, S.I.; Korobkov, I.; Murugesu, M. Slow Magnetic Relaxation in Uranium(III) and Neodymium(III) Cyclooctatetraenyl Complexes. Organometallics 2015, 34, 1415-1418. [CrossRef]

40. Li, Q.-W.; Wan, R.-C.; Chen, Y.-C.; Liu, J.-L.; Wang, L.-F.; Jia, J.-H.; Chilton, N.F.; Tong, M.-L. Unprecedented hexagonal bipyramidal single-ion magnets based on metallacrowns. Chem. Commun. 2016, 52, 13365-13368. [CrossRef] [PubMed]

41. Rinehart, J.D.; Long, J.R. Slow magnetic relaxation in homoleptic trispyrazolylborate complexes of neodymium(III) and uranium(III). Dalton Trans. 2012, 41, 13572-13574. [CrossRef] [PubMed]

42. Demir, S.; Meihaus, K.R.; Long, J.R. Slow magnetic relaxation in a neodymium metallocene tetraphenylborate complex. J. Organomet. Chem. 2018, 857, 164-169. [CrossRef]

43. Baldoví, J.J.; Clemente-Juan, J.M.; Coronado, E.; Duan, Y.; Gaita-Ariño, A.; Giménez-Saiz, C. Construction of a General Library for the Rational Design of Nanomagnets and Spin Qubits Based on Mononuclear f-Block Complexes. The Polyoxometalate Case. Inorg. Chem. 2014, 53, 9976-9980. [CrossRef] [PubMed]

44. Zhang, H.-L.; Wu, X.-Y.; Liao, J.-Z.; Kuang, X.-F.; Yang, W.; Lu, C.-Z. A novel trigonal propeller-shaped hybrid tri-neodymium-polyoxometalate exhibiting single-molecule magnet behavior. Dalton Trans. 2018, 47, 1796-1800. [CrossRef] [PubMed]

45. Berta, C.; Mercè, F.-B.; Saskia, S.; Salah, E.F.M.; Ramon, V. Field-Induced SMM and Visible/NIR-Luminescence Behaviour of Dinuclear Ln ${ }^{\text {III }}$ Complexes with 2-Fluorobenzoate. Eur. J. Inorg. Chem. 2018, 2018, 1928-1937. 
46. Casanovas, B.; Speed, S.; Maury, O.; El Fallah, M.S.; Font-Bardía, M.; Vicente, R. Dinuclear Ln ${ }^{\mathrm{III}}$ Complexes with 9-Anthracenecarboxylate Showing Field-Induced SMM and Visible/NIR Luminescence. Eur. J. Inorg. Chem. 2018, 34, 3859-3867. [CrossRef]

47. Arauzo, A.; Lazarescu, A.; Shova, S.; Bartolome, E.; Cases, R.; Luzon, J.; Bartolome, J.; Turta, C. Structural and magnetic properties of some lanthanide ( $\mathrm{Ln}=\mathrm{Eu}(\mathrm{III}), \mathrm{Gd}(\mathrm{III})$ and $\mathrm{Nd}(\mathrm{III})$ ) cyanoacetate polymers: Field-induced slow magnetic relaxation in the Gd and Nd substitutions. Dalton Trans. 2014, 43, 12342-12356. [CrossRef] [PubMed]

48. Jassal, A.K.; Aliaga-Alcalde, N.; Corbella, M.; Aravena, D.; Ruiz, E.; Hundal, G. Neodymium 1D systems: Targeting new sources for field-induced slow magnetization relaxation. Dalton Trans. 2015, 44, 15774-15778. [CrossRef] [PubMed]

49. Chen, Y.-C.; Huang, X.-S.; Liu, J.-L.; Tong, M.-L. Magnetic Dynamics of a Neodymium(III) Single-Ion Magnet. Inorg. Chem. 2018, 57, 11782-11787. [CrossRef] [PubMed]

50. Gupta, S.K.; Rajeshkumar, T.; Rajaraman, G.; Murugavel, R. An unprecedented zero field neodymium(III) single-ion magnet based on a phosphonic diamide. Chem. Commun. 2016, 52, 7168-7171. [CrossRef] [PubMed]

51. Bar, A.K.; Kalita, P.; Singh, M.K.; Rajaraman, G.; Chandrasekhar, V. Low-coordinate mononuclear lanthanide complexes as molecular nanomagnets. Coord. Chem. Rev. 2018, 367, 163-216. [CrossRef]

52. Rinehart, J.D.; Long, J.R. Exploiting single-ion anisotropy in the design of f-element single-molecule magnets. Chem. Sci. 2011, 2, 2078-2085. [CrossRef]

53. Yi, X.; Bernot, K.; Pointillart, F.; Poneti, G.; Calvez, G.; Daiguebonne, C.; Guillou, O.; Sessoli, R. A Luminescent and Sublimable Dy-III-Based Single-Molecule Magnet. Chem.-Eur. J. 2012, 18, 11379-11387. [CrossRef] [PubMed]

54. Long, J.; Guari, Y.; Ferreira, R.A.S.; Carlos, L.D.; Larionova, J. Recent advances in luminescent lanthanide based Single-Molecule Magnets. Coord. Chem. Rev. 2018, 363, 57-70. [CrossRef]

55. Boulon, M.E.; Cucinotta, G.; Luzon, J.; Degl'Innocenti, C.; Perfetti, M.; Bernot, K.; Calvez, G.; Caneschi, A.; Sessoli, R. Magnetic Anisotropy and Spin-Parity Effect Along the Series of Lanthanide Complexes with DOTA. Angew. Chem. Int. Edit. 2013, 52, 350-354. [CrossRef] [PubMed]

56. Cucinotta, G.; Perfetti, M.; Luzon, J.; Etienne, M.; Car, P.-E.; Caneschi, A.; Calvez, G.; Bernot, K.; Sessoli, R. Magnetic Anisotropy in a Dysprosium/DOTA Single-Molecule Magnet: Beyond Simple MagnetoStructural Correlations. Angew. Chem. Int. Ed. 2012, 51, 1606-1610. [CrossRef] [PubMed]

57. Guegan, F.; Riobe, F.; Maury, O.; Jung, J.; Le Guennic, B.; Morell, C.; Luneau, D. Teaching an old molecule new tricks: Evidence and rationalisation of the slow magnetisation dynamics in [DyTp 2 Acac]. Inorg. Chem. Front. 2018, 5, 1346-1353. [CrossRef]

58. Errulat, D.; Gabidullin, B.; Hemmer, E.; Murugesu, M. Probing Optical Anisotropy and PolymorphDependent Photoluminescence in [ $\left.\mathrm{Ln}_{2}\right]$ Complexes via Hyperspectral Imaging on Single Crystals. Chem. Eur. J. 2018, 24, 10146-10155. [CrossRef] [PubMed]

59. Marx, R.; Moro, F.; Dorfel, M.; Ungur, L.; Waters, M.; Jiang, S.D.; Orlita, M.; Taylor, J.; Frey, W.; Chibotaru, L.F.; et al. Spectroscopic determination of crystal field splittings in lanthanide double deckers. Chem. Sci. 2014, 5, 3287-3293. [CrossRef]

60. Gorczynski, A.; Marcinkowski, D.; Kubicki, M.; Loffler, M.; Korabik, M.; Karbowiak, M.; Wisniewski, P.; Rudowicz, C.; Patroniak, V. New field-induced single ion magnets based on prolate $\mathrm{Er}(\mathrm{III})$ and $\mathrm{Yb}(\mathrm{III})$ ions: Tuning the energy barrier $\mathrm{U}_{\text {eff }}$ by the choice of counterions within an $\mathrm{N}_{3}$-tridentate Schiff-base scaffold. Inorg. Chem. Front. 2018, 5, 605-618. [CrossRef]

61. Karbowiak, M.; Rudowicz, C.; Nakamura, T.; Murakami, R.; Ishida, T. Spectroscopic and magnetic studies of erbium(III)-TEMPO complex as a potential single-molecule magnet: Interplay of the crystal-field and exchange coupling effects. Chem. Phys. Lett. 2016, 662, 163-168. [CrossRef]

62. Ren, M.; Bao, S.-S.; Ferreira, R.A.S.; Zheng, L.-M.; Carlos, L.D. A layered erbium phosphonate in pseudo-D ${ }_{5 h}$ symmetry exhibiting field-tunable magnetic relaxation and optical correlation. Chem. Commun. 2014, 50, 7621-7624. [CrossRef] [PubMed]

63. Palacios, M.A.; Titos-Padilla, S.; Ruiz, J.; Herrera, J.M.; Pope, S.J.A.; Brechin, E.K.; Colacio, E. Bifunctional $\mathrm{Zn}^{\mathrm{II}} \mathrm{Ln}^{\mathrm{III}}$ Dinuclear Complexes Combining Field Induced SMM Behavior and Luminescence: Enhanced NIR Lanthanide Emission by 9-Anthracene Carboxylate Bridging Ligands. Inorg. Chem. 2014, 53, 1465-1474. [CrossRef] [PubMed] 
64. Jiménez, J.R.; Díaz-Ortega, I.F.; Ruiz, E.; Aravena, D.; Pope, S.J.A.; Colacio, E.; Herrera, J.M. Lanthanide Tetrazolate Complexes Combining Single-Molecule Magnet and Luminescence Properties: The Effect of the Replacement of Tetrazolate $\mathrm{N}_{3}$ by $\beta$-Diketonate Ligands on the Anisotropy Energy Barrier. Chem. Eur. J. 2016, 22, 14548-14559. [CrossRef] [PubMed]

65. Martin-Ramos, P.; Coutinho, J.T.; Ramos Silva, M.; Pereira, L.C.J.; Lahoz, F.; da Silva, P.S.P.; Lavin, V.; Martin-Gil, J. Slow magnetic relaxation and photoluminescent properties of a highly coordinated erbium(III) complex with dibenzoylmethane and 2,2'-bipyridine. New J. Chem. 2015, 39, 1703-1713. [CrossRef]

66. Kishi, Y.; Cornet, L.; Pointillart, F.; Riobé, F.; Lefeuvre, B.; Cador, O.; Guennic, B.L.; Maury, O.; Fujiwara, H.; Ouahab, L. Luminescence and Single-Molecule-Magnet Behaviour in Lanthanide Coordination Complexes Involving Benzothiazole-Based Tetrathiafulvalene Ligands. Eur. J. Inorg. Chem. 2018, 2018, 458-468. [CrossRef]

67. Soussi, K.; Jung, J.; Pointillart, F.; Le Guennic, B.; Lefeuvre, B.; Golhen, S.; Cador, O.; Guyot, Y.; Maury, O.; Ouahab, L. Magnetic and photo-physical investigations into Dy ${ }^{\mathrm{III}}$ and $\mathrm{Yb}^{\mathrm{III}}$ complexes involving tetrathiafulvalene ligand. Inorg. Chem. Front. 2015, 2, 1105-1117. [CrossRef]

68. Jung, J.; da Cunha, T.T.; Le Guennic, B.; Pointillart, F.; Pereira, C.L.M.; Luzon, J.; Golhen, S.; Cador, O.; Maury, O.; Ouahab, L. Magnetic Studies of Redox-Active Tetrathiafulvalene-Based Complexes: Dysprosium vs. Ytterbium Analogues. Eur. J. Inorg. Chem. 2014, 2014, 3888-3894. [CrossRef]

69. Cosquer, G.; Pointillart, F.; Jung, J.; Le Guennic, B.; Golhen, S.; Cador, O.; Guyot, Y.; Brenier, A.; Maury, O.; Ouahab, L. Alkylation Effects in Lanthanide Complexes Involving Tetrathiafulvalene Chromophores: Experimental and Theoretical Correlation between Magnetism and Near-Infrared Emission. Eur. J. Inorg. Chem. 2014, 2014, 69-82. [CrossRef]

70. Pointillart, F.; Le Guennic, B.; Golhen, S.; Cador, O.; Maury, O.; Ouahab, L. A redox-active luminescent ytterbium based single molecule magnet. Chem. Commun. 2013, 49, 615-617. [CrossRef] [PubMed]

71. Li, Q.-W.; Liu, J.-L.; Jia, J.-H.; Chen, Y.-C.; Liu, J.; Wang, L.-F.; Tong, M.-L. “Half-sandwich” YbIII single-ion magnets with metallacrowns. Chem. Commun. 2015, 51, 10291-10294. [CrossRef] [PubMed]

72. Ruiz, J.; Lorusso, G.; Evangelisti, M.; Brechin, E.K.; Pope, S.J.A.; Colacio, E. Closely-Related ZnII $\mathrm{LnIII}_{2}$ Complexes $(\mathrm{LnIII}=\mathrm{Gd}, \mathrm{Yb})$ with Either Magnetic Refrigerant or Luminescent Single-Molecule Magnet Properties. Inorg. Chem. 2014, 53, 3586-3594. [CrossRef] [PubMed]

73. Li, Q.-W.; Liu, J.-L.; Jia, J.-H.; Leng, J.-D.; Lin, W.-Q.; Chen, Y.-C.; Tong, M.-L. Fluorescent single-ion magnets: Molecular hybrid $\left(\mathrm{HNEt}_{3}\right)$ [Dyx $\mathrm{Yb}_{1-\mathrm{x}}(\mathrm{bpyda})_{2}$ ] $(\mathrm{x}=0.135-1)$. Dalton Trans. 2013, 42, 11262-11270. [CrossRef] [PubMed]

74. Bain, G.A.; Berry, J.F. Diamagnetic Corrections and Pascal's Constants. J. Chem. Educ. 2008, 85, 532. [CrossRef] 